\title{
Talasemi Majorlu Adolesan Hastalarda Hipofiz-Tiroid Aksı ve Tiroid Fonksiyonlarının İncelenmesi*
}

\author{
Ayşe Şahin ${ }^{1 \dagger}$, Fügen Pekün ${ }^{2}$ \\ ${ }^{1}$ Sağlık Bilimleri Üniversitesi Şişli Hamidiye Etfal Eğitim Araştırma Hastanesi Çocuk Kliniği \\ ${ }^{2}$ Bahçeşehir Üniversitesi, Medical Park Göztepe Hastanesi, Çocuk Hematoloji Kliniği
}

(İlk Geliş Tarihi 16 Ekim 2020 ve Kabul Tarihi 5 Aralık 2020)

(DOI: 10.31590/ejosat.811576)

ATIF/REFERENCE: Şahin, A. \& Pekün, F. (2020). Talasemi Majorlu Adolesan Hastalarda Hipofiz-Tiroid Aksı ve Tiroid Fonksiyonlarının İncelenmesi. Avrupa Bilim ve Teknoloji Dergisi, (20), 703-711.

\section{$\ddot{O} z$}

Talasemi majorlu hastalarda modern tedavi yaklaşımları ile hastaların yaşam süresi uzamış, yaşam kalitesi artmıştır, ancak kronik hipoksi, anemi ve demir birikimine bağlı gelişen endokrin fonksiyon bozuklukları görülmeye devam etmektedir. Çeşitli araştırmalarda TM'lu hastalarda \% 4 ila \% 29 arasında tiroid fonksiyon bozukluğu bildirilmektedir. Bu çalışmada; beta talasemi major ( $\beta$-TM) tanısı ile izlenen hastalarda tiroid bezi ve hipofiz-tiroid aksı fonksiyonlarının incelenmesi ve vücut demir birikiminin bir göstergesi olan ferritin değerleri ile ilişkisi araştırılmıştır.

Gereç ve Yöntem: Çalışmamız prospektif ve tek merkezli olarak tasarlandı. $\beta$-TM tanısı ile izlenen ve düzenli kan transfüzyonu alan 10 yaş ve üzeri 22 olgu çalışmaya dahil edildi. Hastaların demografik yapıları, klinik özellikleri, tiroid bezi ve hipofiz-tiroid aksı fonksiyonlarının incelenmesi amacıyla, bazal tiroid hormonları, Thyroid-Stimulating Hormone (TSH) ve eş zamanlı Thyrotropine Releasing Hormone (TRH) uyarısına TSH yanıtı değerlendirildi. Sonuçlar, serum ferritin değerleri ve sağlıklı kontrollerle karşılaştırıldı.

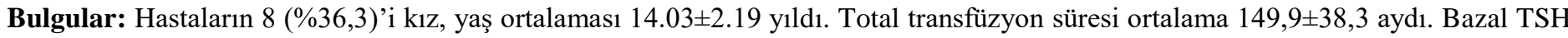
değerleri ile pik TSH değerleri arasında $(\mathrm{r}=0,38, \mathrm{p}<0,05)$ ve bazal TSH ile 60 . dk TSH arasında anlamlı pozitif korelasyon vardı. Olguların \% 27,2'sinde tiroid disfonksiyonu vardı. Üç hastada primer hipotiroidi, iki hastada subklinik düzeyde hipotiroidi, bir hastada hipotalamik hipotiroidi tespit edildi. Sekonder hipotiroidi ve düşük T3 sendromuna rastlanmadi. Ferritin düzeyleri ortalaması $4557,18 \pm 4141,31 \mathrm{ng} / \mathrm{mL}$ idi. Ferritin değerleri ile 20. dk TSH $(\mathrm{r}=0,44, \mathrm{p}<0,05)$ ve $60 . \mathrm{dk} \mathrm{TSH}(\mathrm{r}=0,45, \mathrm{p}<0,05), \Delta \mathrm{TSH}$ ( $\mathrm{r}=0,47, \mathrm{p}<0,05$ ) arasında anlamlı pozitif korelasyon vardı.

Tartışma ve Sonuç: Klinik olarak hipotiroidiye ait semptom ve bulgu vermeyen TM'lu hastalarda hormonal inceleme yapıldığında tiroid disfonksiyonu tespit edilmesi özellikle 10 yaş üzeri TM'lu hastalarda tiroid hormonlarının düzenli aralıklarla takibinin erken tanı ve tedavi açısından önemini ortaya koymaktadır.

Anahtar Kelimeler: Talasemi major; hipofiz-tiroid aksı; tiroid fonksiyonları

\section{Investigation of Pituitary-Thyroid Axis and Thyroid Functions in Adolescent Patients with Thalassemia Major}

\begin{abstract}
With modern treatment approaches in patients with thalassemia major, the life expectancy and quality of life of patients have increased, but chronic hypoxia, anemia and endocrine dysfunction related to iron accumulation continue to be seen. In various studies, thyroid dysfunction has been reported between $4 \%$ and $29 \%$ in patients with TM. In this study; Examination of thyroid gland and pituitary-thyroid axis functions in patients with a diagnosis of beta thalassemia major $(\beta-\mathrm{TM})$ and its relationship with ferritin values, which is an indicator of body iron accumulation, were investigated.
\end{abstract}

\footnotetext{
* Bu makalenin bir bölümü Ulusal Hematololoji Kongresinde Poster olarak sunulmustur. 
Materials and Methods: Our study was designed as a prospective and single center. Twenty-two patients aged 10 years and older who were followed up with a diagnosis of-TM and received regular blood transfusion were included in the study. TSH response to basal thyroid hormones, Thyroid-Stimulating Hormone (TSH) and simultaneous Thyrotropine Releasing Hormone (TRH) stimulation were evaluated in order to examine the demographic structure, clinical characteristics, thyroid gland and pituitary-thyroid axis functions of the patients. Results were compared with serum ferritin values and healthy controls.

Results: Eight (36.3\%) of the patients were female, the mean age was $14.03 \pm 2.19$ years. Total transfusion time was on average $149.9 \pm 38.3$ months. There was a significant positive correlation between basal TSH values and peak TSH values $(r=0.38, p<0.05)$ and between basal TSH and 60th minute TSH. Thyroid dysfunction was present in $27.2 \%$ of the cases. Three patients had primary hypothyroidism, two patients had subclinical hypothyroidism, and one patient had hypothalamic hypothyroidism. Secondary hypothyroidism and low T3 syndrome were not found. The average ferritin levels were $4557.18 \pm 4141.31 \mathrm{ng} / \mathrm{mL}$. There was a significant positive correlation between ferritin values and 20th minute TSH $(r=0.44, \mathrm{p}<0.05)$ and 60th minute TSH $(r=0.45, \mathrm{p}$ $<0.05), \Delta \mathrm{TSH}(\mathrm{r}=0.47, \mathrm{p}<0.05)$.

Discussion and Conclusion: Detecting thyroid dysfunction when hormonal examination is performed in patients with TM who do not have clinical symptoms and symptoms of hypothyroidism, especially in patients over 10 years of age, regular monitoring of thyroid hormones in terms of early diagnosis and treatment reveals its importance.

Key words: Thalassemia Major; Pituitary-Thyroid Axis; Thyroid functions

\section{Giriş}

Beta talasemi major (ß-TM), beta globin zincirinin eksikliği veya tamamen yokluğuna bağlı gelişen ağır anemi ve inefektif eritropoez ile karakterize otozomal resesif geçişli herediter bir kan hastalığıdır (1). Bu hastalarda, düzenli kan transfüzyonları ile birlikte demir şelasyon tedavisi standart tedaviyi oluşturmaktadır. S1k transfüzyon ve artan demir emilimi ile vücutta aşırı demir birikimi olmaktadır (2). Demir birikimi, toksik oksijen radikallerinin açığa çıkmasına yol açarak, protein hasarına, hücre membranındaki lizozom ve mitokondrilerde lipid peroksidasyonuna arac1lık ederek hücre ölümü ve organ yetmezliği tablolarına neden olur (3). Talasemili hastalarda, boy kısalığı, puberte gecikmesi, diyabet, hipoparatiroidi, hipotiroidi en sık görülen endokrin komplikasyonlardır. Demir birikimi endokrin komplikasyonların ana nedeni olarak bilinmektedir (4). Tüm organlarda olduğu gibi, demir tiroid interstisyumunda birikerek hemosideroza neden olur. Tiroid disfonksiyonu esas olarak bezin infiltrasyonu, kronik doku hipoksisi, serbest radikal oluşumu ve organ siderozu ile oluşur (5). TM'lu hastalarda, hipotiroidi sıklığı farklı raporlarda \% 4 ile \% 29 arasında değişmektedir. $\mathrm{Bu}$ durum, hastaların genotipi, yaşı, etnik heterojenliği, transfüzyon ve şelasyon tedavi protokolleri ve tedaviye değişen uyum gibi çeşitli faktörlerden kaynaklanmaktadır (6). Talasemili hastalarda, hipotiroidi gelişimi, vucut demir yükü ile ilişsilidir, demir yükü az olan hastalarda, fazla olanlara göre tiroid disfonksiyonunun daha az görüldüğünü bildiren çalışmalar mevcuttur (7). Desferrioksaminle demir şelasyon tedavisine geç başlayan veya tedaviye zayıf uyum gösteren hastalarda tiroid disfonksiyonu daha erken başlamaktadır (5).

$\mathrm{Bu}$ çalışmada; 10 yaş ve üzeri, $\beta$-TM tanısı ile izlenen hastalarda tiroid bezi ve hipofiz-tiroid aksı fonksiyonlarının incelenmesi, tiroid disfonksiyonunun sıklığının tespit edilmesi ve vücut demir birikiminin bir göstergesi olan serum ferritin düzeyleri ile arasındaki ilişkinin değerlendirilmesi amaçlanmıştır.

\section{Gereç ve Yöntemler}

Çalışmamız, Okmeydanı Eğitim ve Araştırma Hastanesi Çocuk Hematoloji kliniğinde yürütüldü. Çalışma, Okmeydanı Eğitim Araştırma Hastanesi Etik Kurulu (Etik kurul onay no: 48670771-806.01.03) tarafindan onayland.
TM tanısı ile takip edilen 22 olgu $(14.05 \pm 2.19$ yil $)$ çalışmaya dahil edildi. 10 yaş altı TM'lu hastalar ve transfüzyon bağımlı olmayan talasemi hastaları çalışma dışı bırakıldı. Kontrol grubu olarak, herhangi bir nedenle çocuk polikliniğine başvuran, sağlıklı, anemisi ve guatrı olmayan, 10 sağlıklı çocuk çalışmaya alındı, yaş ortalaması $14.05 \pm 2.19$ yıldı. TM tanısı aile öyküsü, hemoglobin elektroforezi ve transfüzyon bağımlılığına dayanıyordu.

Olguların tanı zamanları, ilk transfüzyon yaşları, total transfüzyon süreleri, transfüzyon öncesi Hemoglobin değerleri, ferritin düzeyleri, demir şelasyon tedavisine başlama yaşı, uyum, hasta aileleri ile görüşülerek ve hasta dosyalarından alınan bilgiler esas alınarak kaydedildi.

Hastalara, standart bir tedavi protokolü olarak, hemoglobin seviyelerini $9 \mathrm{gr} / \mathrm{dl}$ 'nin üstünde tutmak amaciyla ortalama 3 haftada bir transfüzyon uygulanmaktaydı. Tüm hastalar şelasyon tedavisi olarak Desferrioksamin B (DFO) (Desferal, Novartis) almaktayd. DFO'i portatif pompa yoluyla 12 saat sürekli subkutan infüzyon ile $40 \mathrm{mg} / \mathrm{kğ} /$ gün, haftada 5 gün kullanmaktaydilar (6). Desferrioksamin tedavisine uyum, önerilen tedavinin \% 90'ını almışsa iyi, \% 50-90 orta, \% 50'nin altında ise kötü klinik uyum olarak değerlendirildi (8). Tüm kan örnekleri, hastaların düzenli transfüzyon başvuruları sırasında, aç olarak saat 08:00 ile 10:00 arasında alındı. Tiroid fonksiyonlarını değerlendirmek amacıyla bazal tiroid hormonlar1, serum free triiodothyronine (ST3), free thyroxine (ST4), total triiodothyronine (TT3), total thyroxine (TT4), Thyroid-stimulating hormone (TSH ) ve eşzamanlı Thyrotropine Releasing Hormone (TRH) uyarısına TSH yanıtı değerlendirildi. Bazal TSH için kan alındıktan sonra $7 \mu \mathrm{g} / \mathrm{kg} / \mathrm{doz}$ TRH intravenöz verildikten sonra 0,20 ve 60 . dakikalarda TSH için kan örnekleri alındı (9). Pik TSH ve $\Delta \mathrm{TSH}$ (bazal değere göre yükselme) saptandı. Tiroid hormonları için alınan kan örnekleri çalışmanın yapılacağı güne kadar - 20 derecede saklandı ve Hastanemiz Nükleer Tıp Merkezi RIA laboratuvarında çalışıldı. Bazal tiroid hormonlarının değerlendirilmesinde, kontrol grubunun ortalama değerlerinin 2 SD altındaki değerler patolojik kabul edildi. TRH uyarı testinin sonuçları ise kontrol grubunun TSH değerlerinin alt sınırından düşük ve üst sınırından yüksek değerler patolojik olarak değerlendirildi $(10,11)$.

Tiroid disfonksiyonu şu şekilde tanımlandı; 1. Normal (Bazal TT3, TT4, sT3, sT4, TSH ve TRH uyarısına TSH yanıtı normal). 2. Subklinik primer hipotiroidi ( sT4 ve TSH normal 
(5-10 ng/ml), TRH uyarısına artmış TSH yanıtı). 3. Kompanse primer hipotiroidi (sT4 normal, bazal TSH artmış). 4. Dekompanse primer hipotiroidi (sT4 azalmış, TSH > $10 \mathrm{ng} / \mathrm{ml}$ ). 5. Tersiyer hipotiroidi: TRH'ya gecikmiş TSH yanıtı. 6. Sekonder hipotiroidi (TRH'ya künt TSH yanıtı ) $(9,10)$.

Hastaların fizik gelişimleri için ağırlık ve boy ölçümleri persentil olarak değerlendirildi. Boy yaşı ve boy için ortadan sapma (Boy SDS, Z skor ) hesaplandı (12).

Karaciğer, dalak büyüklüğü $\mathrm{cm}$ olarak ölçüldü, Tiroid bezi palpasyonla değerlendirildi ve Dünya Sağlık Örgütü (WHO) tarafindan önerilen guatr sinıflandırma sistemine göre değerlendirildi (13). Ciltte kuruluk kabalaşma gibi hipotiroidiye ait bulgular arand.

Puberte gelişimi için Tanner evrelemesi yapıldı (14). Kemik yaşı tayini, sol el bilek grafisinin Grulich WW. Pyle SI atlasına göre yapıld1 (15).

Hastaların, $\mathrm{TT}_{3}, \mathrm{TT}_{4}, \mathrm{sT}_{3}, \mathrm{sT}_{4}$, TSH düzeyleri ve eşzamanlı TRH uyarısına TSH yanıtı, serum ferritin düzeyleri, trasfüzyon durumları ve şelasyon tedavisi ile ilişkisi değerlendirildi. Ferritin düzeyleri ile pik TSH, 60. dk TSH ve $\Delta \mathrm{TSH}$ arasındaki ilişki araştırıld 1

İstatistiksel analiz için SPSS 15.0 for Windows programı kullanıldı. Tanımlayıcı istatistikler; kategorik değişkenler için Tablo 1. Hasta grubu genel özellikleri

\begin{tabular}{|c|c|c|}
\hline \multirow{3}{*}{ Cinsiyet $\quad \mathrm{n}(\%)$} & & $\mathrm{N}=22$ \\
\hline & Erkek & $14(63,6)$ \\
\hline & Kadın & $8(36,4)$ \\
\hline Takvim Yașı (yıl) Ort. \pm SD & & $14,03 \pm 2,19$ \\
\hline \multirow{2}{*}{$\begin{array}{l}\text { Kemik Yaşı (yıl) } \text { Ort. } \pm \text { SD } \\
\text { \% Boy n }(\%)\end{array}$} & & $11,59 \pm 2,20$ \\
\hline & $3 \mathrm{P}>$ & $11(50,0)$ \\
\hline & $3 \mathrm{P}$ & $2(9,1)$ \\
\hline & $10-25 \mathrm{P}$ & $4(18,2)$ \\
\hline & $25-50 \mathrm{P}$ & $1(4,5)$ \\
\hline Z Skoru Ort. \pm SD & & $-2,07 \pm 1,05$ \\
\hline \multirow[t]{2}{*}{ Puberte Evresi n $(\%)$} & $\mathrm{P} 1$ & $4(18,2)$ \\
\hline & $\mathrm{P} 2$ & $9(40,9)$ \\
\hline İlk Transfüzyon Yaşı $\quad$ Ort. \pm SD & & $18,52 \pm 17,23$ \\
\hline Total Transfüzyon Yaşı Ort. \pm SD & & $149,91 \pm 38,36$ \\
\hline $\begin{array}{ll}\text { Total Transfüzyon Yaşı Ort. } \pm \text { SD } \\
\text { Ferritin } & \text { Ort. } \pm \text { SD }\end{array}$ & & $3921,05 \pm 3372,72$ \\
\hline DF başlama yaşı & & $5,64 \pm 2,17$ \\
\hline \multirow{2}{*}{$\begin{array}{l}\text { DF başlama yaşı } \\
\text { DF Düzeni }\end{array}$} & İyi & $7(31,8)$ \\
\hline & Kötü & $8(36,4)$ \\
\hline & Orta & $7(31,8)$ \\
\hline Ort. \pm SD & & $71,27 \pm 67,98$ \\
\hline Ort. \pm SD & & $55,23 \pm 35,18$ \\
\hline Karaciğer Büyüklüğü (cm) Ort. \pm SD & & $4,80 \pm 2,83$ \\
\hline
\end{tabular}

sayı ve yüzde, sayısal değişkenler için ortalama, standart sapma olarak verildi. Bağımsız iki grup karşılaştırmaları sayısal değişkenler normal dağılım koşulunu sağladığında Student t Test, normal dağılım koşulunu sağlamadığında Mann Whitney U testi ile yapıldı. Sayısal değişkenler arası ilişkiler parametrik test koşulu sağlanmadığından Spearman Korelasyon Analizi ile incelendi. İstatistiksel alfa anlamlılık seviyesi $\mathrm{p}<0,05$ olarak kabul edildi.

\section{Bulgular}

Çalışmaya 10 yaş ve üzerinde 22 TM'lu hasta alındı, yaş ortalaması $14,03 \pm 2,19$ yıl $(10,33$ ile 18.08 yıl $), \quad 14$ ü $(\% 63,6)$ erkekti. Kontrol grubunun yaş ortalaması 14,05 $\pm 2,21$ yıl, 7'si gelişimleri, ilk transfüzyon yaşı, total transfüzyon süresi, pretransfüzyon ortalama $\mathrm{Hb}$ değerleri, demir şelasyon tedavisine başlama yaşı, uyumu ve ferritin değerleri Tablo 1'de özetlendi. Hastalarımız üç haftada bir transfüzyon almakta ve demir şelasyon tedavisi amaciyla desferrioksamin (subkutan 8-12 saatlik infüzyon şeklinde $40 \mathrm{mg} / \mathrm{kg} /$ gün, haftada beş gün) kullanmaktaydılar. Transfüzyon tedavisine başlama yaşı 3 ay ile 72 ay arasında değişmekteydi ( ort: 18,52 $\pm 17,23$ ). Total transfüzyon süresi 54 ay ile 194 ay (ort 149,9 $\pm 38,3$ ) arasındaydı. (\%70) erkekti. Hastaların fizik özellikleri ve pubertal

DF: Desferal, ALT: Alanin aminotransferaz, AST: Aspartataminotransferaz

Hastalarımız karaciğer tutulumu açısından değerlendirildiğinde, $2 \mathrm{~cm}$ ile $12 \mathrm{~cm}$ arasında karaciğer büyüklüğü tespit edildi. ALT ve AST 13 hastada yükselmişti. 12 hastada her ikisi beraber yüksek bulundu (Tablo 1). ALT sonuçları ile ferritin düzeyleri karşılaştırıldığında, istatistiksel olarak anlamlı bir ilişki saptanmadı. 
Tablo 2. Tiroid hormonları, TRH uyarısına TSH yanıtları ve kontrol grubu ile karşılaştırılması

\begin{tabular}{|c|c|c|c|c|}
\hline & & Hasta Grup $(n=22)$ & Kontrol Grubu $(n=10)$ & \\
\hline \multirow[t]{3}{*}{ Bazal Hormon Değerleri } & TT4 & $10,68 \pm 2,12$ & $10,59 \pm 2,36$ & 0,915 \\
\hline & sT3 & $5,15 \pm 1,43$ & $4,65 \pm 0,98$ & 0,325 \\
\hline & sT4 & $1,55 \pm 0,21$ & $1,77 \pm 0,44$ & 0,063 \\
\hline \multirow[t]{2}{*}{ TRH uyarisına yanıtlar } & Pik TSH & $21,01 \pm 7,87$ & $22,57 \pm 5,90$ & 0,581 \\
\hline & $\Delta$ TSH & $18,00 \pm 7,08$ & $19,71 \pm 5,81$ & 0,510 \\
\hline
\end{tabular}

TT3; Total triiodothyronine, TT4; Total thyroxine, sT3Serbest triiodothyronine, ST4; Serbest thyroxine, TSH; Thyroid-Stimulating Hormone, TRH; Thyrotropine Releasing Hormone

Hastalarımızda \% 27,2 oranında tiroid disfonksiyonu saptand1. Tiroid bezi ve hipofiz-tiroid aksı fonksiyonlarına ait incelemelerde hastaların bazal tiroid hormonları ( TT3, ST3, TT4, ST4, TSH) ve TRH uyarısına TSH yanıtları Tablo 2'de verilmiştir. Bir olgu dişında tüm hastalar pik TSH değerine 20. dk'da ulaşıldı. Hasta grubumuzda bazal tiroid hormonları kontrollerle karşılaştırıldığında arada istatistiksel olarak anlamlı bir fark bulunamadi. Aynı zamanda TRH uyarısına pik TSH ve $\triangle \mathrm{TSH}$ değerlerinin ortalaması kontrollere göre hafif düşük olmakla beraber aradaki fark istatistiksel olarak anlamlı değildi
(Tablo 2). Hastalarımız kontrol grubu referans alınarak değerlendirildiğinde; üç hastada kompanse primer hipotiroidi, iki hastada subklinik primer hipotiroidi, bir hastada hipotalamik hipotiroidi tespit edildi.

Hastalarımızın bazal TSH değerleri ile pik TSH değerleri arasında anlamlı pozitif korelasyon tespit edildi ( $\mathrm{r}=0.38$, $\mathrm{p}<0.05$ ) (Grafik 2a). Aynı şekilde bazal TSH ile 60. dakika TSH arasında da anlamlı pozitif korelasyon vardı $(\mathrm{r}=0.42, \mathrm{p}<0.05)$ (Grafik 2b).

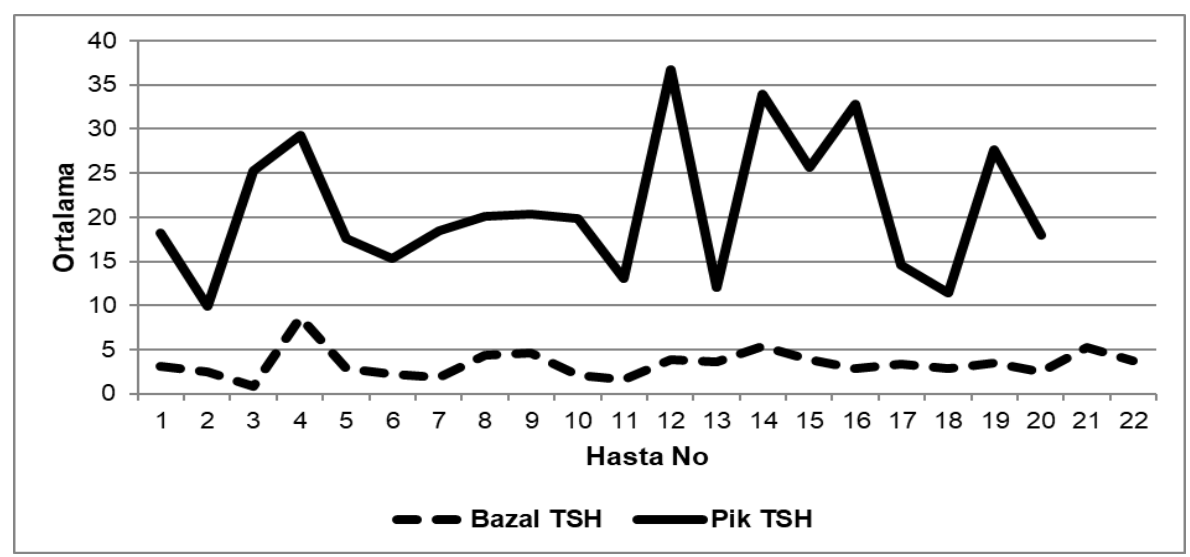

Grafik 2 a. Bazal TSH ile pik TSH arasındaki ilişki

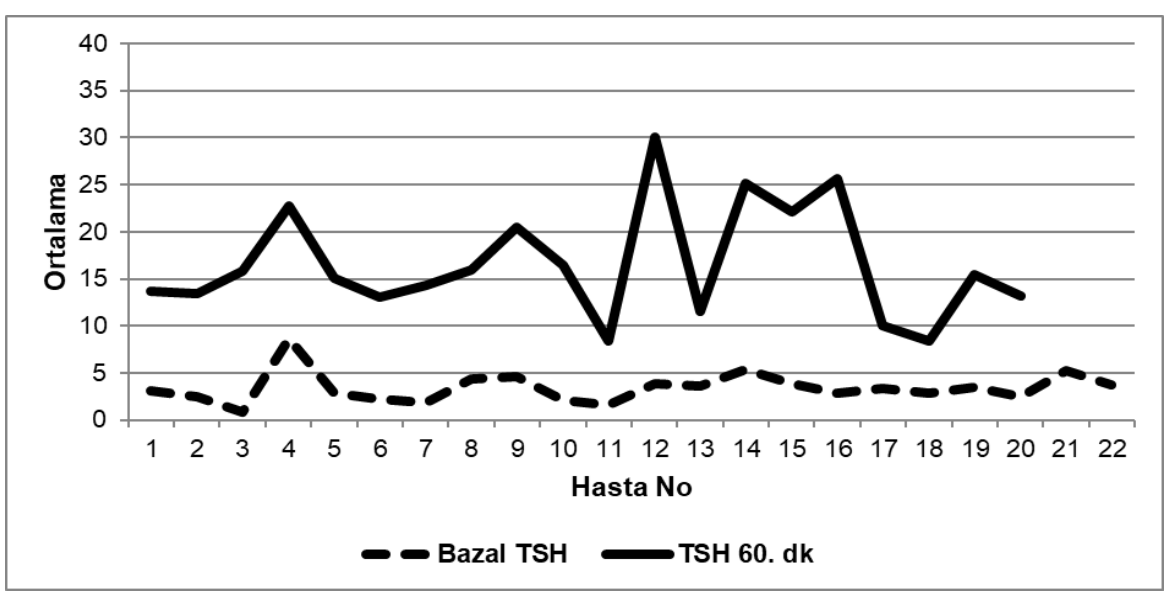

Grafik 2 b. Bazal TSH ile 60. dk TSH ilişkisi 
Ferritin düzeyleri ortalaması $4557.18 \pm 4141.31 \mathrm{ng} / \mathrm{ml}$ idi. Ferritin değerleri ile 20. dk TSH ( r=0,44, p<0,05) (Grafik 3 a) ve 60 . $\mathrm{dk}$ TSH $(\mathrm{r}=0,45, \mathrm{p}<0,05)$ (grafik $3 \mathrm{~b}$ ), $\Delta \mathrm{TSH}(\mathrm{r}=0,47, \mathrm{p}<0,05)$ (Grafik $3 \mathrm{c}$ ) arasında anlamlı pozitif korelasyon vardı.

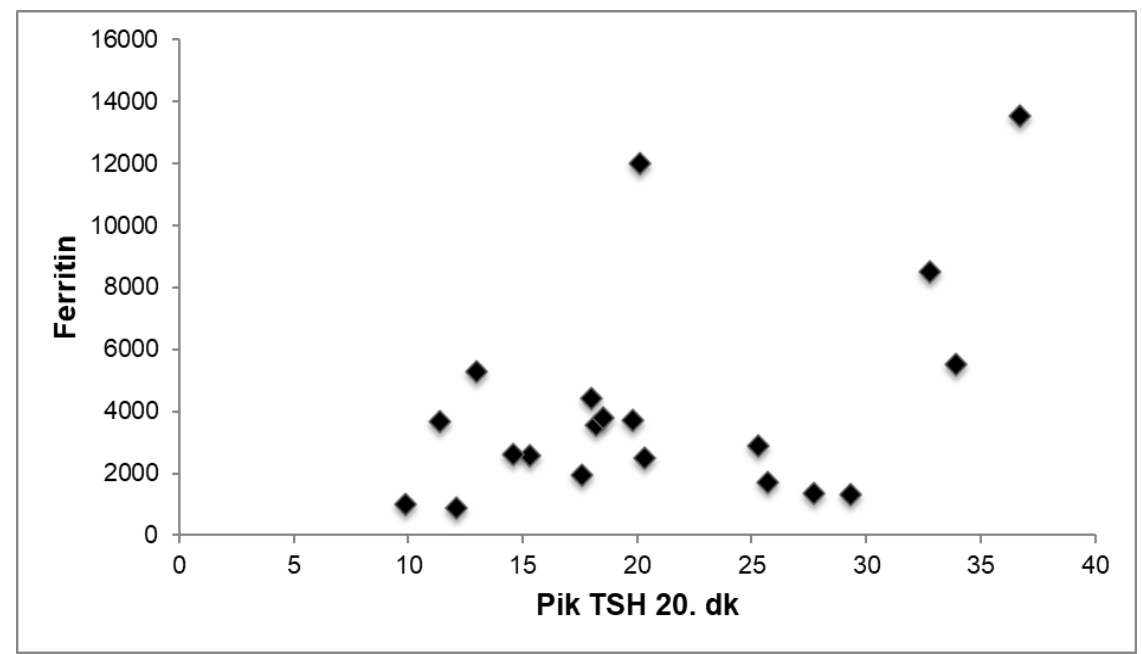

Grafik 3 a. Ferritin ile 20. dk TSH korelasyonu

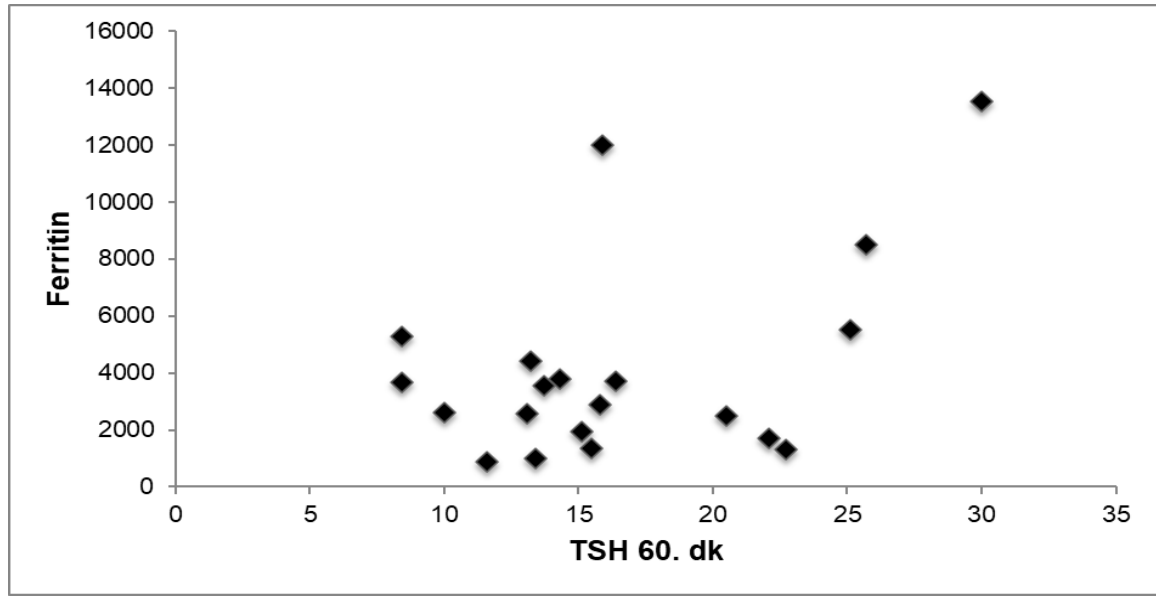

Grafik 3 b. Ferritin ile 60. dk TSH ilişkisi

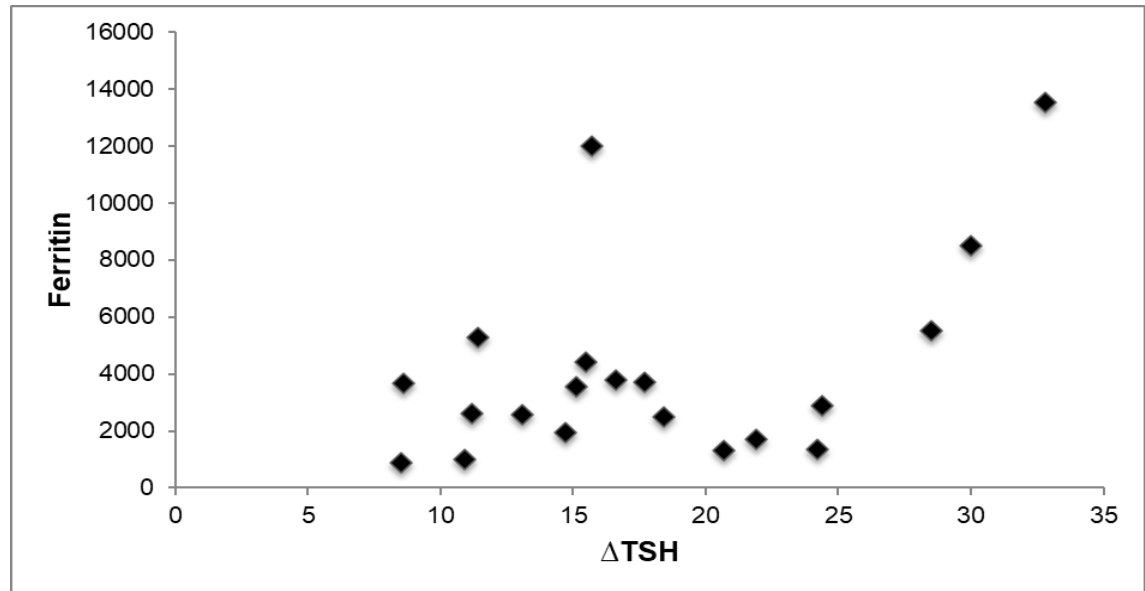

Grafik 3 c. Ferritin ile $\Delta$ TSH korelasyonu

Olgularımızı tek tek incelediğimizde, 11,5 yaşında bir erkek hastada, TSH ve sT4 ve TT4 değerleri normaldi, TRH uyarısına gecikmiş TSH yanıtı (pik TSH değerine 60. dakikada ulaştı) ve hasta, santral hipotiroidi lehine değerlendirildi. Olgumuzda hipotalamik pataloji açısından başka bulgular yoktu. İki hastamız, bazal TSH ve sT4'ün normal olması ve TRH uyarısına artmış TSH yanıtı ile subklinik primer hipotiroidi olarak değerlendirildi Üç hastamızda bazal TSH yüksek, sT4 
değerlerinin normal olduğu kompanse primer hipotiroidi tespit edildi. Aynı zamanda bu olgulardan TRH uyarı testi yapılan iki hastada abartılı yanıt elde edildi. Diğer olguya uyarı testi yapılmamıştı.

Boy gelişimi 12 hastada 3. persentilin altındaydı (\%54,5) yaş için verilen ortalama değerden standart sapmaları (Boy SDS,
Z skoru) ortalamas1 $-2,06 \pm 1,04$ yıl ( 0,24 ile $-4,12$ arasında). Boy yaşı ortalaması 10,8 $\pm 1,6$ yıl idi. Hastalarımızda ileri derecede büyüme geriliği vardı. Hastaların çoğunda kemik yaşı geriliği belirgindi. Kızların \% 75'inde erkeklerin \%92'sinde kemik yaş1

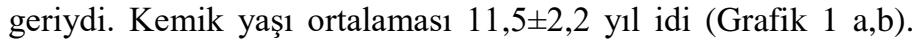

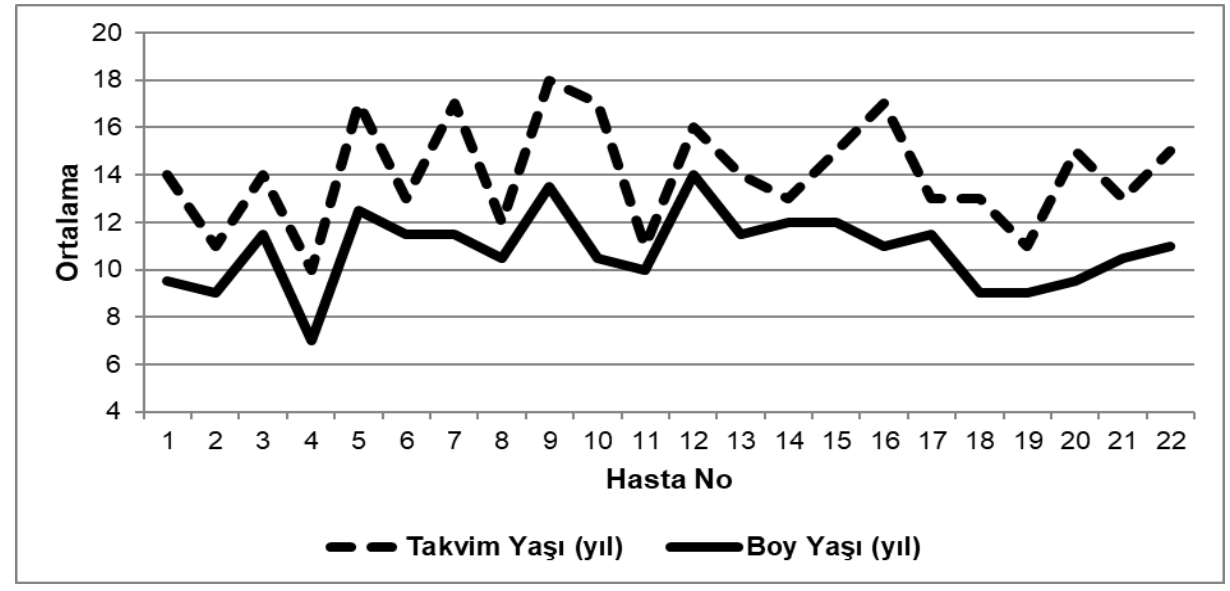

Grafik 1.a Takvim yaşı ile boy yaşının karşılaştırılması

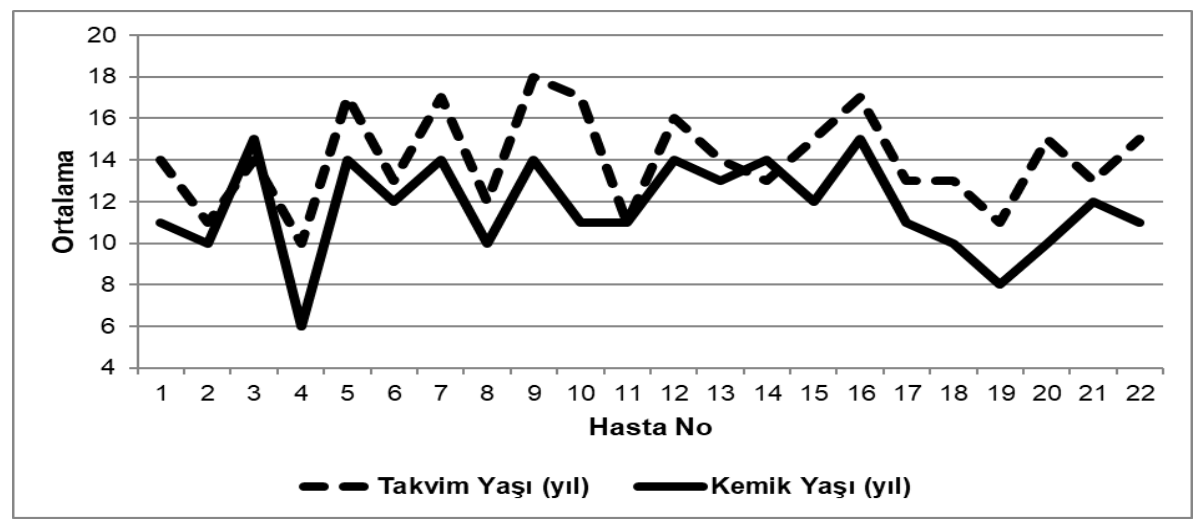

Grafik 1 b. Takvim yaşı ile kemik yaşının karşılaştırılması

Pubertal gelişim açısından değerlendirildiğinde kızlardan beş hastada $\mathrm{P}_{3}(\% 62.5)$, iki hastada $\mathrm{P} 2$ (\%25), bir hasta $\mathrm{P} 4$ ( \% 12.5) evresindeydi. Erkeklerden dört hasta prepubertal evredeydi. Yedi hasta P2 (\%70), iki hasta P3 (\%20), bir hasta P5 (\% 10) evresindeydi (Tablo 1).

\section{Tartışma}

Temel tedavi yaklaşımı düzenli aralıklarla transfüzyon ve şelasyon tedavisi olan $\beta$-TM'lu hastalar, aşırı demir birikimi açısından risk altındadırlar (5). $\beta$-TM'lu hastalarda tiroid bezi ve hipofiz- tiroid aksı fonksiyonlarına ait bir çok çalışma $(18,19,20)$. Bazı çalışmalarda normal tiroid fonksiyonu bildirilirken $(16,17)$, \%60'lara varan oranda tiroid disfonksiyonu rapor eden çalışmalar da mevcuttur. B-TM'lu hastalarda primer hipotiroidi sıklığı \% 4 ile \% 29 arasında değişmektedir, genel olarak subklinik hipotiroidi, aşikar hipotiroidiye göre daha yaygındır. $\mathrm{Bu}$ geniş varyasyonun, hastaların yaşı, sayısı, etnisitesi, transfüzyon tedavi protokollerindeki farklılık, şelasyon tedavisine uyum gibi faktörlere bağlı olabileceğini düşünülmektedir (6). Sabato ve ark. nın 114 olguluk yaş ortalaması 13,6 yıl olduğu çalışmada kompanse ve dekompanse primer hipotiroidi sıklığını \% 17,5 oranında tespit etmişlerdir (11).

Tiroid disfonksiyonunu daha yüksek oranlarda bulanlardan Magro ve ark. 60 hastalık serilerinde toplamda \% 51,7 oranında olmak üzere, \% 15 subklinik, \% 18,3 kompanse, \% 13,3 dekompanse primer hipotiroidi saptamışlardır (10).

Uzun yıllar izlem sonucu yapılan çalışmalar, ilerleyen yaşla birlikte tiroid fonksiyonlarının kötüleştiğini göstermiştir, aşikar hipotiroidinin ortaya çıkması yıllar alabilmektedir. De Sanctis ve ark.'nın yaptı̆̆ı bir çalışmada 24 TM hastasının 8'inde (\%33.3) TRH testine abartılı TSH yanıtı saptanmış, sekiz hastanın üçü 11 yıl içinde subklinik veya aşikar hipotiroidi geliştirmiştir. TRH testinden sonra TSH pik değerlerinin, ferritin ile pozitif korelasyon gösterdiği tespit edilmiştir (19). Landau ve ark.'nın yaş ortalamasının 21 olduğu 37 hasta ile yapılan 15 yıllık takibi içeren bir çalışmalarında, TM'lu hastaların \% 30'undan fazlasının TRH'ya anormal yanıt verdiğini ve \% 
14'ünün de normalden aşikar hipotiroidiye döndüğünü bildirmişlerdir (18). Yine Zervas ve ark. ortalama tiroid hormon değeri olan 5 TM'lu hastadan birinin TRH testine abartılı bir TSH yanıtı verdiğini rapor etmişlerdir (3).

Bizim çalışmamızda, bazal tiroid hormonları kontrollerle karşılaştırıldığında arada istatistiki olarak anlamlı bir fark bulunamadi. TSH düzeyleri kontrollerden hafif yüksek olmakla beraber aradaki fark anlamlı değildi. Hastalarımızın TRH uyarısına pik TSH ve $\triangle \mathrm{TSH}$ değerleri kontrollere göre hafif düşük olmakla beraber aradaki fark istatistiki olarak anlamlı değildi. Livades ve ark'nın 7 hastalık serilerinde TRH'ya TSH yanıtını TM'lu hastalarda kontrolllerden anlamlı düşük bulmuşlar ve hastalarda hem hipofizer hem de tiroid fonksiyon bozukluğunun olduğunu öne sürmüşlerdir (20). Çalışmamızda, $\%$ 27,2 oranında tiroid fonksiyon bozukluğu tespit ettik. Tiroid disfonksiyonu saptadığımız üç hastada TT3 ve s T3 düzeylerini yüksek bulduk. $\mathrm{Bu}$ durumun tiroid bezinin kompansasyonuna bağlı daha fazla T3 sentez etmesi nedeniyle olduğunu düşündürdü. Tiroid fonksiyonları normal saptanan iki hastamızda da sT3 değerleri yüksek bulundu; bu hastalarda diğer tiroid hormonları ve TRH' ya TSH yanıtı normaldi, hipertiroidiye ait bulgu yoktu. sT3 değerlerindeki yüksekliğin, tiroksin reseptörlerindeki duyarsızlığa veya reseptör duyarlılığındaki görece azalmaya bağlı olabileceğini düşündük.

Bir hastamızda, TSH ve sT4 ve TT4 değerlerinin normal, TRH uyarısına gecikmiş TSH yanıtı (pik TSH değerine 60. dakikada ulaştı) olduğu görüldü ve santral hipotiroidi lehine değerlendirildi, hipotalamik pataloji açısından başka bir bulguya rastlanmadı. Santral hipotiroidinin tanısı klinik ve biyokimyasal açıdan zor konulmaktadır. Santral hipotiroidi sıklığının araştırıldığı, yaş ortalamasının 30 yaş olduğu bir çalışmada 21 yaş altı TM'lu hastalarda \% 6 oranında, 21 yaş üstü hastalarda ise \%7,9 gibi yüksek oranda görüldüğü bildirilmiştir (21). Son yıllarda, farklı ülkelerden verilerin toplandığı bir çalışmada erişkin $\beta$-TM'lu hastalarda en s1k rastlanan komplikasyonun, santral hipotiroidi $(\% 4,6)$ ve büyüme hormonu eksikliği $(\% 3)$ olduğu rapor edilmiştir (22). Yıllar içinde, TM'lu hastalarda santral hipotiroidi tanısının konulmasında önemli gelişmeler sağlanmış ve farkındalık artmıştır. $\mathrm{Bu}$ durumda, hem hipotalamus, hem de hipofiz bezinin aşırı demir yüklenmesinden etkilendiği düşünülmektedir (6).

TRH stimülasyon testi, tiroid disfonksiyonunun erken tanıs1 için yararalı bir araç olabilir. TRH testine abartılı bir TSH yanıtı TM'da siklıkla vardır ve bu durum subklinik ve ya klinik hipotiroidiye dönüşebilmektedir. Bu komplikasyonların erken tanı ve tedavisi, iyi bir yaşam kalitesi sağlamak ve geç morbidite ve mortaliteyi azaltmak için gereklidir (6).

Tiroid disfonksiyonu saptadığımız üç hastamızda TT3 ve s T3 düzeylerini yüksek bulduk. Bu durum bize, bu hastalardaiyot eksikliğinin de eşlik edebileceğini düşündürdü. Ancak spot idrar iyot eksikliğinin değerlendirilmesinde yeterli olmayıp ortalama on örnekleme gerektiği bilinmektedir.Tiroid fonksiyonları normal saptanan iki hastamızda da sT3 değerleri yüksek bulundu, bu hastalarda diğer tiroid hormonları ve TRH' ya TSH yanıtı normaldi, hipertiroidiye ait bulgu yoktu. Hastalarımızda hipotiroidiyi düşündürecek klinik bulguya rastlamadık. Yapılan çalışmalarda da klinik olarak TM'lu hastalar ötiroid bulunmakta, hormonal inceleme yapıldığında tiroid disfonksiyonu tespit edilmektedir $(9,19,23)$

Serum ferritininin vücut demir depoları ile ilişkili olduğu bilinmektedir. Ferritin değerlerinin seri ölçümü, demir e-ISSN: 2148-2683 yüklenmesi ve şelasyon tedavisinin etkinliğini değerlendirmek için güvenilir ve en kolay yöntemdir (24). TM'lu hastalarda tiroid disfonksiyonunun sebebi artmış demir birikimi gibi görünmekle birlikte çalışmalarda birbirinden farklı sonuçlar bildirilmiştir. Bazı araştırıcılar tiroid fonksiyon bozukluğu ile ilk transfüzyon yaş1, total transfüzyon sayıs1, ferritin düzeyleri arasında ilişki saptayamamışlar $(10,11,18,25)$. Ferritin ile tiroid disfonksiyonu arasındaki ilişkiyi araştıran farklı çalışmalarda ise, Chirico ve ark. ferritin düzeyinin hem tiroid disfonksiyonunda hem de ilerlemesinde önemli bir prognostik faktör olduğunu göstermiştir (4). Al-Hader ve ark. 90 TM'lu hastayı ferritin değerlerine göre ( WHO kriterleri) 300-7000 $\mathrm{ng} / \mathrm{ml}$ olanları hafif demir yüklenmesi, $7000 \mathrm{ng} / \mathrm{ml}$ ve üzerinde olanları ciddi demir yüklenmesi olarak iki gruba ayırmışlar ve ciddi demir yüklenmesi olanların hemen hepsinde tiroid disfonksiyonu saptarken diğer grupta çok az oranda tiroid disfonksiyonu tespit etmişler ve demir yüklenmesi ile tiroid disfonksiyonu arasında ilişkiyi ortaya koymuşlardır (26). Yine Gamberini ve ark. ferritin düzeyinin $3000 \mathrm{ng} / \mathrm{ml}$ seviyelerinde olmasının hipotiroidi ile ilişkili olduğunu göstermişlerdir (27).

Bizim çalışmamızda da benzer şekilde, ferritin düzeyleri ile pik TSH, 60. dk TSH, $\triangle \mathrm{TSH}$ arasında anlamlı pozitif korelasyon saptadık, bu bulgu bize tiroid disfonksiyonu oluşumunda demir birikiminin en önemli mekanizma olduğunu düşündürdü. Tiroid disfonksiyonu saptadığımız hastaların yarısında ferritin değerleri çok yüksek ve DFO tedavisini düzensiz kullanmaktaydı. Bununla birlikte ferritin düzeyleri düşük olan ve düzenli DFO kullanan üç hastamızda da tiroid disfonksiyonu saptadık. Aynı zamanda ferritin düzeyi çok yüksek ve DF tedavisine uyumsuz bir hastamıda tiroid fonksiyonları normal bulduk. Bu bulgular bize tiroid disfonksiyonunda demir birikiminin dışında, anemiye ikincil hipoksi ve kronik karaciğer hastalığı gibi diğer faktörlerinde rol oynadığını düşündürdü(10,11,26).

Büyüme gecikmesi B-TM'lu hastaların çarpıcı özelliklerindendir. Dört yaşından sonra büyüme duraklaması, sekiz yaşından sonra boy, oturma yüksekliği, kilo ve iskelet olgunlaşmasını içerecek şekilde ortaya çıkar. Bu yaştan sonra büyümenin yavaşlaması ve pubertal büyüme hızının azalması veya yokluğu gözlenir(16). Büyüme yetmezliğinin patogenezi bir çok faktöre bağlıdır. Temel olarak kronik anemi ve hipoksi, farklı organlarda aşırı demir yükü, kronik karaciğer hastalığı, beslenme yetersizliğine, şelatörlerin düzensiz kullanımına ve endokrinopatilere (hipogonadizm, puberte gecikmesi, hipotiroidzm,büyüme hormonu-insulin benzeri büyüme faktörü1 ( IGF-1) ekseninin disregülasyonu) bağlıdır. Tiroid hormonlar1, büyüme hormonu-IGF-1 sistemi ve boy ve kemik büyümesini kontrol eden diğer hormonlarla etkileşime girer (28).

Hastalarımızda kemik yaşı ve boy yaşı geriliği çok belirgindi. Ancak tiroid fonksiyon testlerinde bozukluk ile kemik yaşı geriliği ve boy yaşı arasında anlamlı bir ilişki tespit saptamadık (29). Hastalarımızın longitudinal izlem verileri bu konuda daha fazla veri elde etmemize yardımcı olacaktır.

\section{Sonuç}

On yaş ve üzerindeki $ß$-TM 'lu hastalarda tiroid bezi ve hipofiz- tiroid aks1 fonksiyonlarının incelenmesi ve serum ferritin düzeyi ile ilişkisinin değerlendirilmesi amacı ile yapılan çalışmamızda, \% 27,2 oranında tiroid disfonksiyonu saptadık., Ferritin düzeyleri ile pik TSH, 60. dk TSH, $\Delta \mathrm{TSH}$ arasında 
anlamlı pozitif korelasyon saptanması demir birikiminin tiroid disfonksiyonunda çok önemli bir faktör olduğunu destekledi. Demir birikiminin tiroid disfonksiyonundaki yeri, şelasyon tedavisinin de önemini vurgulamaktadır.

Hastalarımızda sekonder hipotiroidi ve düşük T3 sendromu saptamadık. Klinik olarak hastalarımızda hipotiroidiyi düşündürecek bulgu ve semptoma rastlanmaması ancak hormonal inceleme yapıldığı zaman tiroid disfonksiyonu tespit edilmesi özellikle 10 yaş üzeri TM'lu hastalarda tiroid hormonlarının (TSH, s T4) düzenli aralıklarla takip edilmesinin önemini ortaya koymaktadır.

\section{Teşekkür}

Yazarlar süreç kapsamında verdiği destekten dolayı Prof. Dr. Hülya Günöz'e teşekkür eder.

\section{Kaynakça}

1. Origa R. (2017). $\beta$-Thalassemia. Genetics in medicine : official journal of the American College of Medical Genetics, 19(6), 609-619.

2. Soliman, A. T., Al Yafei, F., Al-Naimi, L., Almarri, N., Sabt, A., Yassin, M., \& De Sanctis, V. (2013). Longitudinal study on thyroid function in patients with thalassemia major: High incidence of central hypothyroidism by 18 years. Indian journal of endocrinology and metabolism, 17(6), 1090-1095.

3. Zervas, A., Katopodi, A., Protonotariou, A., Livadas, S., Karagiorga, M., Politis, C., \& Tolis, G. (2002). Assessment of thyroid function in two hundred patients with betathalassemia major. Thyroid : official journal of the American Thyroid Association, 12(2), 151-154.

4. Chirico, V., Lacquaniti, A., Salpietro, V., Luca, N., Ferraù, V., Piraino, B., Rigoli, L., Salpietro, C., \& Arrigo, T. (2013). Thyroid dysfunction in thalassaemic patients: ferritin as a prognostic marker and combined iron chelators as an ideal therapy. European journal of endocrinology, 169(6), 785-793.

5. Upadya, S. H., Rukmini, M. S., Sundararajan, S., Baliga, B. S., \& Kamath, N. (2018). Thyroid Function in Chronically Transfused Children with Beta Thalassemia Major: A CrossSectional Hospital Based Study. International journal of pediatrics, 2018, 9071213 .

6. De Sanctis, V., Soliman, A. T., Canatan, D., Yassin, M. A., Daar, S., Elsedfy, H., Di Maio, S., Raiola, G., Corrons, J. V., \& Kattamis, C. (2019). Thyroid Disorders in Homozygous $\beta$-Thalassemia: Current Knowledge, Emerging Issues and Open Problems. Mediterranean journal of hematology and infectious diseases, 11(1), e2019029.

7. Belhoul, K. M., Bakir, M. L., Saned, M. S., Kadhim, A. M., Musallam, K. M., \& Taher, A. T. (2012). Serum ferritin levels and endocrinopathy in medically treated patients with $\beta$ thalassemia major. Annals of hematology, 91(7), 11071114.

8. Richardson, M. E., Matthews, R. N., Alison, J. F., Menahem, S., Mitvalsky, J., Byrt, E., \& Harper, R. W. (1993). Prevention of heart disease by subcutaneous desferrioxamine in patients with thalassaemia major. Australian and New Zealand journal of medicine, 23(6), 656-661.
9. DeGroot LJ. Endocrinology. In: DeGroot LJ, editor. Endocrinology. Toronto: Saunders; 1989. pp. 583601.

10. Magro, S., Puzzonia, P., Consarino, C., Galati, M. C., Morgione, S., Porcelli, D., Grimaldi, S., Tancrè, D., Arcuri, V., \& De Santis, V. (1990). Hypothyroidism in patients with thalassemia syndromes. Acta haematologica, 84(2), 72-76.

11. Sabato, A. R., de Sanctis, V., Atti, G., Capra, L., Bagni, B., \& Vullo, C. (1983). Primary hypothyroidism and the low T3 syndrome in thalassaemia major. Archives of disease in childhood, 58(2), 120-127.

12. Neyzi, O., Furman, A., Bundak, R., Gunoz, H., Darendeliler, F., \& Bas, F. (2006). Growth references for Turkish children aged 6 to 18 years. Acta paediatrica (Oslo, Norway : 1992), 95(12), 1635-1641.

13. Perez C, Scrimshaw S, Munoz A. Technique of endemic goiter surveys. In Endemic Goiter. Geneva: WHO; 1960. pp. 369-383

14. Tanner, J. M., \& Whitehouse, R. H. (1976). Clinical longitudinal standards for height, weight, height velocity, weight velocity, and stages of puberty. Archives of disease in childhood, 51(3), 170-179.

15. Greulich WW, Pyle SI, Radiographic Atlas of Skeletal Development of the Hand and the Wrist (2nd Ed). Stanford University Press, Stanford, CA; 1959

16. Canale, V. C., Steinherz, P., New, M., \& Erlandson, M. (1974). Endocrine function in thalassemia major. Annals of the New York Academy of Sciences, 232(0), 333-345.

17. de Luca, F., Melluso, R., Sobbrio, G., Canfora, G., \& Trimarchi, F. (1980). Thyroid function in thalassaemia major. Archives of disease in childhood, 55(5), 389-392.

18. Landau, H., Matoth, I., Landau-Cordova, Z., Goldfarb, A., Rachmilewitz, E. A., \& Glaser, B. (1993). Cross-sectional and longitudinal study of the pituitary-thyroid axis in patients with thalassaemia major. Clinical endocrinology, 38(1), 55-61.

19. De Sanctis, V., Tanas, R., Gamberini, M. R., Sprocati, M., Govoni, M. R., \& Marsella, M. (2008). Exaggerated TSH response to TRH ("sub-biochemical" hypothyroidism) in prepubertal and adolescent thalassaemic patients with iron overload: prevalence and 20-year natural history. Pediatric endocrinology reviews : PER, 6 Suppl 1, 170-173.

20. Livadas, D. P., Sofroniadou, K., Souvatzoglou, A., Boukis, M., Siafaka, L., \& Koutras, D. A. (1984). Pituitary and thyroid insufficiency in thalassaemic haemosiderosis. Clinical endocrinology, 20(4), 435-443.

21. De Sanctis, V., Soliman, A., Candini, G., Campisi, S., Anastasi, S., \& Iassin, M. (2013). High prevalence of central hypothyroidism in adult patients with $\beta$-thalassemia major. Georgian medical news, (222), 88-94.

22. De Sanctis, V., Soliman, A. T., Canatan, D., Tzoulis, P., Daar, S., Di Maio, S., Elsedfy, H., Yassin, M. A., Filosa, A., Soliman, N., Mehran, K., Saki, F., Sobti, P., Kakkar, S., Christou, S., Albu, A., Christodoulides, C., Kilinc, Y., Al Jaouni, S., Khater, D., ... Kattamis, C. (2019). An ICET-A survey on occult and emerging endocrine complications in patients with $\beta$-thalassemia major: Conclusions and recommendations. Acta bio-medica : Atenei Parmensis, 89(4), 481-489.

23. Flynn, D. M., Fairney, A., Jackson, D., \& Clayton, B. E. (1976). Hormonal changes in thalassaemia major. Archives of disease in childhood, 51(11), 828-836. 
24. De Sanctis, V., Soliman, A., \& Yassin, M. (2013). Iron overload and glucose metabolism in subjects with $\beta$ thalassaemia major: an overview. Current diabetes reviews, 9(4), 332-341.

25. Masala, A., Meloni, T., Gallisai, D., Alagna, S., Rovasio, P. P., Rassu, S., \& Milia, A. F. (1984). Endocrine functioning in multitransfused prepubertal patients with homozygous beta-thalassemia. The Journal of clinical endocrinology and metabolism, 58(4), 667-670.

26. al-Hader, A., Bashir, N., Hasan, Z., \& Khatib, S. (1993). Thyroid function in children with beta-thalassemia major in north Jordan. Journal of tropical pediatrics, 39(2), 107-110.

27. Gamberini, M. R., De Sanctis, V., \& Gilli, G. (2008). Hypogonadism, diabetes mellitus, hypothyroidism, hypoparathyroidism: incidence and prevalence related to iron overload and chelation therapy in patients with thalassaemia major followed from 1980 to 2007 in the Ferrara Centre. Pediatric endocrinology reviews : PER, 6 Suppl 1, 158-169.

28. Soliman AT, Sanctis VD, Elalaily R, Yassin M. Insulin-like growth factor-I and factors affecting it in thalassemia major. Indian J Endocr Metab 2015; 19: 245-51.

29. Borgna-Pignatti, C., De Stefano, P., Zonta, L., Vullo, C., De Sanctis, V., Melevendi, C., Naselli, A., Masera, G., Terzoli, S., \& Gabutti, V. (1985). Growth and sexual maturation in thalassemia major. The Journal of pediatrics, 106(1), 150 155 . 